\title{
Synthesis of NIR-Responsive $\mathrm{NaYF}_{4}: \mathrm{Yb}, \mathrm{Er}$ Upconversion Fluorescent Nanoparticles Using an Optimized Solvothermal Method and Their Applications in Enhanced Development of Latent Fingerprints on Various Smooth Substrates
}

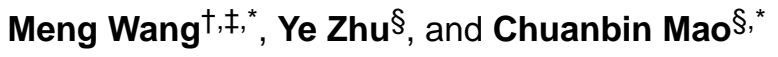 \\ tDepartment of Trace Examination, National Police University of China, Shenyang 110035, \\ People's Republic of China \\ $¥$ Key Laboratory of Impression Evidence Examination and Identification Technology, Ministry of \\ Public Security, Shenyang 110035, People's Republic of China \\ $\S$ Department of Chemistry \& Biochemistry, Stephenson Life Sciences Research Center, \\ University of Oklahoma, Norman, Oklahoma 73019, United States
}

\begin{abstract}
Fingerprints at crime scenes are usually latent. The powder-dusting method is the most commonly used procedure for developing latent fingerprints in forensic science. However, the traditional powder-dusting method has characteristics of low sensitivity, low contrast, high background noise, and high autofluorescence interference. To overcome the drawbacks faced by the traditional method, we first optimized an oleic acid-based solvothermal approach for the synthesis of $\mathrm{NaYF}_{4}: \mathrm{Yb}$,Er fluorescent upconversion nanoparticles (UCNPs) with the highest possible fluorescence intensity under near-infrared (NIR) irradiation. To optimize the synthesis, we studied the effects of the reaction time, reaction temperature, and volume of oleic acid on the size, phase composition, and UC fluorescence intensity of the UCNPs. We then used the resultant UCNPs to fluorescently label the fingerprints on various smooth substrates to improve the development of latent fingerprints because the UCNPs could undergo excitation under $980 \mathrm{~nm}$ NIR light to emit visible light. Latent fingerprints on three major types of smooth substrates were studied, including those with a single background color (transparent glass, white ceramic tiles, and black marbles), with multiple background colors (marbles with different complex surface patterns) and with strong background autofluorescence (note papers, Chinese paper money, and plastic plates). Compared with fingerprint development using traditional powders such as bronze powder, magnetic powder, and green fluorescent powder, our development procedure using UCNPs is facile and exhibits very high sensitivity, high contrast, low background interference, and low autofluorescence
\end{abstract}

\footnotetext{
*Corresponding Authors.cbmao@ou.edu. mengwang@alum.imr.ac.cn. ASSOCIATED CONTENT

Supporting Information

UC fluorescence spectra and XRD patterns of NaYF4:Yb,Er UCNPs synthesized at $150{ }^{\circ} \mathrm{C}$ for $8 \mathrm{~h}$ by using different volumes of oleic acid, UC luminescence decay curve of NaYF4:Yb,Er UCNPs synthesized at $180^{\circ} \mathrm{C}$ for $24 \mathrm{~h}$ with $5 \mathrm{~mL}$ of oleic acid, as well as magnified images of latent fingermarks labeled by $\mathrm{NaYF}_{4} \mathrm{Yb}$, Er UCNPs and traditional powders. The Supporting Information is available free of charge on the ACS Publications website at DOI: 10.1021/acs.langmuir.5b01151.

The authors declare no competing financial interest.
} 
interference. This work shows that UCNPs synthesized under optimized conditions are a versatile fluorescent label for the facile development of fingerprints and can find their practical applications in forensic sciences.

\section{Graphical abstract}

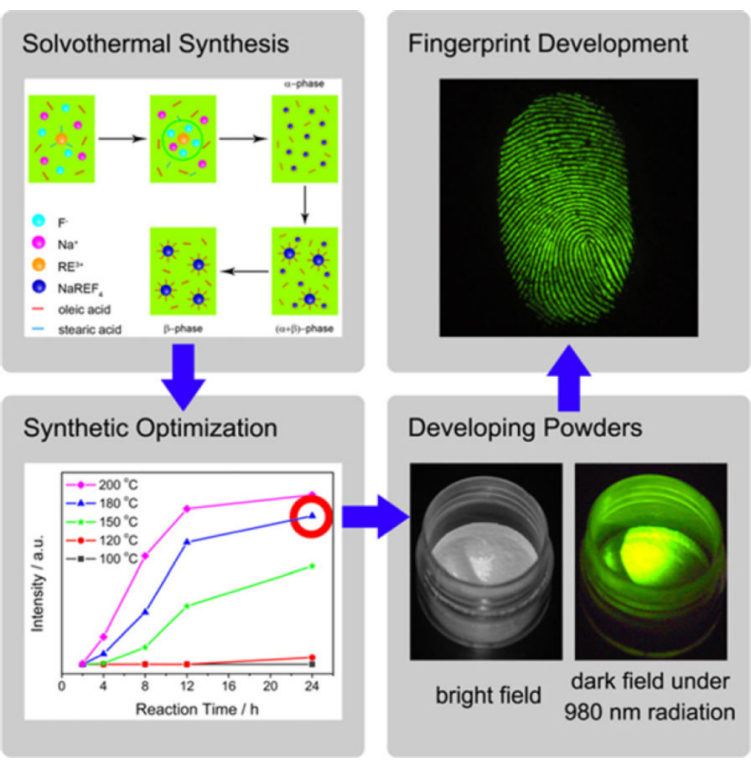

\section{INTRODUCTION}

Fingerprints most commonly found at crime scenes are typically latent, namely, they are normally invisible or poorly visible to investigators. They have to be developed to become visible. Traditional fingerprint development methods include powder dusting, ninhydrin spraying, cyanoacrylate fuming, ${ }^{-}$and silver nitrate soaking. Among these methods, the powder-dusting method is the simplest and most commonly used due to its high efficiency and ease in use. The powders used in this method include metal powders, magnetic powders, and fluorescent powders. Although these powders are effective in the development of latent fingerprints under many ordinary circumstances, powder-dusting methods using these powders are still challenged by serious problems such as low sensitivity, low contrast, high background interference, and high autofluorescence interference.

As an alternative to the traditional powders, fluorescent nanoparticles (NPs) such as quantum dots (QDs) and upconversion nanoparticles (UCNPs) have received great attention for the development of latent fingerprints due to their unique physical and chemical properties such as small particle size, large surface area, good photochemical stability, and high fluorescent intensity.- Among different NPs being studied so far, UCNPs are being considered as ideal probes for developing the latent fingerprints. UCNPs can convert radiation of long wavelength (e.g., near-infrared (NIR) light) into emissions of shorter wavelength (e.g., visible light) via a two-photon or multiphoton mechanism. ${ }^{-}$They are excited by NIR light to emit strong visible fluorescence. Thus, they can enhance the signals, increase sensitivity and contrast, and eliminate background interference for fingerprint 
detection. Other NPs such as QDs often require the use of ultraviolet (UV) radiation, leading to substrate fluorescence and significant autofluorescence interference.,-,- The use of NIR irradiation for inducing UCNPs to emit visible light can avoid significant autofluorescence interference by the substrate. ${ }^{-}$NIR radiation is safe for DNA in fingerprint residuals when used in developing fingerprints and is less harmful to the skin and eyes of the operators than the UV light. In addition, UCNPs exhibit narrow emission peak, large Stokes shift, good chemical and physical stability, and low toxicity.", Therefore, UCNPs are expected to outperform conventional powders and other NPs in latent fingerprint development. Ma et al. reported the use of commercially available $\mathrm{NaYF}_{4}: \mathrm{Yb}$,Er and $\mathrm{YVO}_{4}: \mathrm{Yb}, \mathrm{Er} \mathrm{UC}$ fluorescent particles for developing latent fingerprints on a variety of nonporous and semiporous surfaces. However, these commercial particles were not well-dispersed and not uniform in shape, with a large size ranging from $\sim 0.2$ to $2 \mu \mathrm{m}$. Such large particles with nonuniform shapes could reduce the affinity between the particles and the fingerprint residuals, and even some detailed features of the fingerprints may also be covered by the larger particles, leading to a decreased detection sensitivity. Recently Wang et al. reported the use of a solution of $\mathrm{NaYF}_{4}: \mathrm{Yb}$,Er UCNPs functionalized with lysozyme-binding aptamer for recognizing the lysozyme in the sweat associated with the fingerprints for the detection of fingerprints. However, this method contained complicated steps and was not practical at crime scenes because it required chemical modification of the large UCNPs $(\sim 260 \mathrm{~nm})$ through tedious procedures and long-time incubation of fingerprints with the UCNPs solution for $30 \mathrm{~min}$.

In this work, we optimized a solvothermal approach for they synthesis of $\mathrm{NaYF}_{4}: \mathrm{Yb}, \mathrm{Er}$ UCNPs in order to produce UCNPs with uniform size and strong fluorescent intensity that can be used to develop latent fingerprints (Scheme 1). They were characterized by transmission electron microscopy (TEM), X-ray diffraction (XRD) measurements, and fluorescence spectroscopy. In order to optimize the solvothermal approach, we systematically studied the effects of reaction time, reaction temperature, and volume of oleic acid on the size, phase, and UC fluorescence intensity of the UCNPs. Then we employed the optimized $\mathrm{NaYF}_{4}: \mathrm{Yb}$,Er UCNPs to develop latent fingerprints on the smooth substrates including glass, ceramic tiles, marbles, polymer materials, printing paper and paper money. We found that the use of UCNPs resulted in the clear visualization of the friction ridge details of fingerprints on various smooth substrates while avoiding background or autofluorescence interference under NIR light.

\section{EXPERIMENTAL SECTION}

\subsection{Materials}

Rare-earth oxides including yttrium oxide $\left(\mathrm{Y}_{2} \mathrm{O}_{3}\right)$, ytterbium oxide $\left(\mathrm{Yb}_{2} \mathrm{O}_{3}\right)$, and erbium oxide $\left(\mathrm{Er}_{2} \mathrm{O}_{3}\right)$ all had $99.99 \%$ purity. Sodium fluoride $(\mathrm{NaF})$, stearic acid $\left(\mathrm{C}_{17} \mathrm{H}_{35} \mathrm{COOH}\right)$, oleic acid $\left(\mathrm{C}_{17} \mathrm{H}_{33} \mathrm{COOH}\right)$, sodium hydroxide $(\mathrm{NaOH})$, and nitric acid $\left(\mathrm{HNO}_{3}\right)$ were of analytical grade. All of these chemicals were purchased from Sinopharm Chemical Reagent Co., Ltd. (Shanghai, China). The control powders, including commercially available bronze powder, magnetic powder, and green fluorescent powder, were purchased from Beijing Fenge Science \& Technology Co., Ltd. (Beijing, China). Triple-distilled water was used throughout the experiments. 


\subsection{Characterization}

The UCNPs were imaged under a JEM-2100HR transmission electron microscope (JEOL Ltd., Japan) using an accelerating voltage $200 \mathrm{kV}$. They were characterized by XRD on an X'Pert Pro diffractometer (PANalytical Co., Holland) with graphite monochromatized $\mathrm{Cu}$ Ka radiation $(\lambda=0.15406 \mathrm{~nm})$. The diffractometer was performed with scanning done in the $2 \theta$ range of $10^{\circ}$ to $80^{\circ}$ at a rate of $8 \% \mathrm{~min}$. UC fluorescence spectra of the dried powdered NPs were measured on an LS-55 fluorescence spectrophotometer (PerkinElmer Co., USA) using an external $980 \mathrm{~nm}$ laser source (Beijing Hi-Tech Optoelectronic Co., China) instead of internal excitation source. The dynamic light scattering (DLS) measurements were performed on a Nano ZS90 zetasizer (Malvern Instruments Ltd., UK). The latent fingerprints labeled with UCNPs were excited by a $980 \mathrm{~nm}$ laser (Suzhou Xiaosong Technology Co., Ltd. China) equipped with an extending lens. A Nikon D800 digital camera equipped with an AF-S Nikkor 24-70 $\mathrm{mm}$ f/2.8G ED lens was used to take the photographs of the developed fingerprints.

\subsection{Synthesis of $\mathrm{NaYF}_{4}: \mathrm{Yb}, \mathrm{Er}$ UCNPs}

2.3.1. Synthesis of Rare-Earth Stearates Precursors-Rare-earth stearates were used as a precursor. To synthesize the rare-earth stearates, a mixture of $0.8807 \mathrm{~g}$ of $\mathrm{Y}_{2} \mathrm{O}_{3}$, $0.3941 \mathrm{~g}$ of $\mathrm{Yb}_{2} \mathrm{O}_{3}$, and $0.0383 \mathrm{~g}$ of $\mathrm{Er}_{2} \mathrm{O}_{3}$ was first dissolved in nitric acid followed by heating. The resulting nitrate powder was obtained after the solvent was removed by drying. The as-prepared powder and $8.5344 \mathrm{~g}$ of stearate acid were dissolved with stirring in $80 \mathrm{~mL}$ of ethanol at $78{ }^{\circ} \mathrm{C}$ in a flask. Another solution containing $1.1900 \mathrm{~g}$ of $\mathrm{NaOH}$ and $20 \mathrm{~mL}$ of ethanol was added dropwise to the flask within $30 \mathrm{~min}$. The resulting mixture was then refluxed at $78{ }^{\circ} \mathrm{C}$ for $40 \mathrm{~min}$. Precipitates from the reaction mixture were filtered under decompression and washed, first with water twice and then with ethanol once. The precursor powder was obtained after the precipitates were dried at $60^{\circ} \mathrm{C}$ for $12 \mathrm{~h}$.

\subsubsection{Synthesis of $\mathrm{NaYF}_{4}: \mathrm{Yb}, \mathrm{Er}$ UCNPs by a Solvothermal Approach-}

Mixing of $10 \mathrm{~mL}$ of water, $15 \mathrm{~mL}$ of ethanol, and $5 \mathrm{~mL}$ of oleic acid under stirring resulted in a homogeneous solution, to which the precursor powder $(0.9578 \mathrm{~g})$ and $\mathrm{NaF}(0.2099 \mathrm{~g})$ were added. The resulting mixture was sonicated for $15 \mathrm{~min}$, transferred to a $50 \mathrm{~mL}$ autoclave, sealed, and then solvothermally treated at $180^{\circ} \mathrm{C}$ for $24 \mathrm{~h}$. After air-cooling of the autoclave to room temperature, $\mathrm{NaYF}_{4}: \mathrm{Yb}$,Er UCNPs were deposited at the bottom of the vessel and then collected by a mixture of chloroform and ethanol (1:6, v/v). The UCNPs were purified by centrifugation, washed twice with a mixture of water and ethanol $(1: 2, \mathrm{v} / \mathrm{v})$, and then dried at $60{ }^{\circ} \mathrm{C}$ for $12 \mathrm{~h} . \mathrm{NaYF}_{4}: \mathrm{Yb}$,Er UCNPs were thus obtained.

\subsection{Detection of Latent Fingerprints Using $\mathrm{NaYF}_{4}: \mathrm{Yb}, \mathrm{Er}$ UCNPs}

Latent fingerprints on three major types of smooth substrates were studied, including those with a single background color (transparent glass, white ceramic tiles and black marbles), with multiple background colors (marbles with complex patterns) and with strong background autofluorescence (note papers, Chinese paper money and plastic plates). To collect fingerprints from the same donor, fingers from a clean hand were gently wiped across the forehead. Then latent fingerprints were pressed onto the surfaces of the substrates. To 
detect the latent fingerprints, $\mathrm{NaYF}_{4}: \mathrm{Yb}$,Er UCNPs in the form of dry powder were carefully deposited onto the surface of the substrates, followed by a light brushing action to remove the excess powder. A Nikon D800 digital camera, which was attached with an AF-S Nikkor 24-70 $\mathrm{mm} \mathrm{f} / 2.8 \mathrm{G}$ ED lens and a $980 \mathrm{~nm}$ laser light, was used to photograph the images of the fingerprints.

\section{RESULTS AND DISCUSSION}

\subsection{Effect of Synthetic Conditions}

3.1.1. Effect of Reaction Time-TEM images of $\mathrm{NaYF}_{4}$ : $\mathrm{Yb}$,Er UCNPs synthesized at $150{ }^{\circ} \mathrm{C}$ for 2, 8, and $24 \mathrm{~h}$ are shown in Figure 1a,b,c, respectively. The corresponding histograms of the particle diameter were also shown in Supporting Information Figure S1. UCNPs synthesized for $2 \mathrm{~h}$ were roughly spherical and small ( $\sim 15 \mathrm{~nm}$ size); however, they were not well-dispersed and tended to aggregate (Figure 1a). When the reaction time was increased to $8 \mathrm{~h}$, the UCNPs became well-dispersed and spherical, increasing in size to 25 $\mathrm{nm}$ (Figure 1b). At $24 \mathrm{~h}$, the UCNPs became larger $(\sim 35 \mathrm{~nm})$ with the shape and dispersibility almost unchanged (Figure 1c).

$\mathrm{NaREF}_{4}$ (RE refers to rare-earth) at ambient pressure have two forms: the cubic a-phase (metastable, high-temperature phase) and the hexagonal $\beta$-phase (thermodynamically stable, low-temperature phase). The $\beta$-phase can be obtained from the a-phase via cubic-tohexagonal phase transition under extreme conditions.' Figure 2 shows the XRD patterns of $\mathrm{NaYF}_{4}$ : $\mathrm{Yb}, \mathrm{Er}$ UCNPs synthesized at $150{ }^{\circ} \mathrm{C}$ for 2,8 , and $24 \mathrm{~h}$. It shows that UCNPs synthesized for $2 \mathrm{~h}$ were in cubic a-phase $\mathrm{NaYF}_{4}$. At $8 \mathrm{~h}$, in addition to the cubic a-phase, hexagonal $\beta$-phase $\mathrm{NaYF}_{4}$ (JCPDS No. 28-1192) appeared, suggesting that UCNPs synthesized at $150{ }^{\circ} \mathrm{C}$ for $8 \mathrm{~h}$ were a mixture of the major cubic a-phase and minor hexagonal $\beta$-phase resulting from cubic-to-hexagonal phase transition. At $24 \mathrm{~h}$, the hexagonal $\beta$-phase was the only phase that could be detected by XRD, indicating that the hexagonal $\beta$-phase was successfully synthesized at $150^{\circ} \mathrm{C}$ after $24 \mathrm{~h}$.

Figure 3 shows UC fluorescence spectra of $\mathrm{NaYF}_{4}: \mathrm{Yb}$,Er UCNPs synthesized at $150{ }^{\circ} \mathrm{C}$ for $2,4,8,12$, and $24 \mathrm{~h}$. UCNPs synthesized for 2 and $4 \mathrm{~h}$ nearly had no fluorescence because UCNPs were in cubic a-phase $\mathrm{NaYF}_{4}: \mathrm{Yb}$,Er UCNPs that gave almost no emission. When the reaction time increased from 8 to $12 \mathrm{~h}$, the fluorescence intensity obviously increased due to the formation of the fluorescent hexagonal $\beta$-phase. Furthermore the fluorescence intensity was enhanced significantly from 12 to $24 \mathrm{~h}$ because the fluorescent hexagonal $\beta$ phase became the dominant phase and eventually the only phase. Therefore, the fluorescence data are in good agreement with the XRD patterns.

3.1.2. Effect of Reaction Temperature-Figure 4a,b,c exhibits the TEM images of $\mathrm{NaYF}_{4}$ : $\mathrm{Yb}, \mathrm{Er} \mathrm{UCNPs}$ synthesized for $8 \mathrm{~h}$ at 100,150 , and $200{ }^{\circ} \mathrm{C}$, respectively. The corresponding histograms of the particle diameter were also shown in Figure S2. UCNPs synthesized at $100{ }^{\circ} \mathrm{C}$ were roughly spherical, small ( $\sim 15 \mathrm{~nm}$ size), and poorly dispersed (Figure $4 \mathrm{a})$. At a higher temperature, larger and well-dispersed UCNPs were obtained ( 30 $\mathrm{nm}$ at $150{ }^{\circ} \mathrm{C}$, and $35 \mathrm{~nm}$ at $200{ }^{\circ} \mathrm{C}$; Figure $\left.4 \mathrm{~b}, \mathrm{c}\right)$, indicating that longer reaction time and higher temperature will favor the growth of the UCNPs. 
Figure 5 depicts the XRD patterns of $\mathrm{NaYF}_{4}: \mathrm{Yb}$,Er UCNPs synthesized for $8 \mathrm{~h}$ at 100,150 , and $200^{\circ} \mathrm{C}$. When the temperature was relatively low $\left(100^{\circ} \mathrm{C}\right)$, only pure cubic a-phase could be formed. At a higher temperature $\left(150^{\circ} \mathrm{C}\right)$, a few diffraction peaks indexed to hexagonal $\beta$-phase appeared along with peaks for the cubic a-phase. When the temperature was further increased to $200{ }^{\circ} \mathrm{C}$, intensities of peaks belonging to the hexagonal $\beta$-phase increased dramatically, indicating the continued cubic-to-hexagonal phase transition.

However, the cubic a-phase was not completely converted to the hexagonal $\beta$-phase at a reaction temperature of $200{ }^{\circ} \mathrm{C}$ at $8 \mathrm{~h}$. These data show that reaction time and temperature determine the phase of $\mathrm{NaYF}_{4}: \mathrm{Yb}$,Er UCNPs and that sufficiently long reaction time and high temperature are required to promote the cubic-to-hexagonal phase transition. They also show that pure cubic a-phase UCNPs could be prepared at low temperature (e.g., $\triangleleft 10{ }^{\circ} \mathrm{C}$ ) and within a short reaction time (e.g., $\mathcal{s}$ h).

Figure 6 shows UC fluorescence spectra of $\mathrm{NaYF}_{4}: \mathrm{Yb}, \mathrm{Er}$ UCNPs synthesized at 100, 120, 150,180 , and $200{ }^{\circ} \mathrm{C}$ for $8 \mathrm{~h}$. The fluorescence intensity remained almost unchanged when the temperature was relatively low $\left(100\right.$ and $\left.120^{\circ} \mathrm{C}\right)$. However, the fluorescence intensity was increased with the increase in temperature from 120 to $200{ }^{\circ} \mathrm{C}$. Consistent with the XRD patterns, these results further suggest that a higher reaction temperature is needed to increase the amount of hexagonal $\beta$-phase in $\mathrm{NaYF}_{4}: \mathrm{Yb}$,Er UCNPs and consequently to enhance the UC fluorescence intensity.

3.1.3. Effect of Volume of Oleic Acid- $\mathrm{NaYF}_{4}: \mathrm{Yb}, \mathrm{Er}$ UCNPs were synthesized from rare-earth precursors in a water-ethanol-oleic acid system via a solvothermal approach. Thus, it is expected that the use of oleic acid would influence the phase content and UC fluorescence intensity of $\mathrm{NaYF}_{4}: \mathrm{Yb}, \mathrm{Er} \mathrm{UCNPs}$. Figure $\mathrm{S} 3$ shows UC fluorescence spectra of the $\mathrm{NaYF}_{4}$ : $\mathrm{Yb}$,Er UCNPs synthesized with different amounts of oleic acid for $8 \mathrm{~h}$ at $150{ }^{\circ} \mathrm{C}$. When the volume of oleic acid was $3 \mathrm{~mL}$, the fluorescence intensity of the UCNPs was moderate. When the volume of oleic acid was increased from 4 to $5 \mathrm{~mL}$, the fluorescence intensity of the UCNPs was increased. However, the fluorescence intensity was decreased when the volume of oleic acid was further increased to $6 \mathrm{~mL}$. Therefore, there exists an optimal amount of oleic acid $(\sim 5 \mathrm{~mL})$. In order to understand such a trend, XRD characterization was conducted to find out the change in the phase compositions of the products at different concentrations of oleic acid. The XRD patterns (Figure S4 in the Supporting Information) and UC fluorescence spectra of $\mathrm{NaYF}_{4}$ : Yb,Er UCNPs (Figure S3 in the Supporting Information) collectively confirm that adding a moderate amount of oleic acid $(5 \mathrm{~mL})$ to the reaction system favored the cubic-to-hexagonal phase transition of UCNPs, resulting in an increase in the hexagonal phase and the UC fluorescence intensity. Excess oleic acid inhibited cubic-to-hexagonal phase transition, resulting in a decrease in the amount of the hexagonal phase and UC fluorescence intensity. Hence, $5 \mathrm{~mL}$ was determined to be the optimal volume for the synthesis of UCNPs with the highest UC fluorescence intensity. 


\subsection{Use of $\mathrm{NaYF}_{4}: \mathrm{Yb}, \mathrm{Er}$ UCNPs for Developing Latent Fingerprints on Various Substrates}

$\mathrm{NaYF}_{4}: \mathrm{Yb}$,Er UCNPs were synthesized at the optimized solvothermal conditions (at a temperature of $180^{\circ} \mathrm{C}$ for $24 \mathrm{~h}$ with $5 \mathrm{~mL}$ oleic acid) to reach the strongest fluorescence, and the lifetime of the corresponding UCNPs was $212 \mu \mathrm{s}$, which was calculated from the UC luminescence decay curves (Figure S5 in the Supporting Information). The as-prepared UCNPs were then used as fluorescent labels for developing latent fingerprints on various smooth substrates, including those with a single background color (transparent glass, white ceramic tiles, and black marbles), with multiple background colors (marbles with complex patterns) and with strong background autofluorescence (note papers, Chinese paper money, and plastic plates). In addition, as a control labeling powder, conventional powders such as bronze powder, magnetic powder, and green fluorescent powder were also used to develop the fingerprints.

\subsubsection{Development of Latent Fingerprints on Normal Substrates With Single} Background Color-To determine the development of contrast between the labeled fingerprint and the background in latent fingerprint development using $\mathrm{NaYF}_{4}: \mathrm{Yb}, \mathrm{Er}$ UCNPs as fluorescence labels, smooth objects (transparent glass, white ceramic tiles, and black marbles) with a single background color were chosen as substrates. Fingerprints labeled with bronze powders showed high contrast when the background color was dark (Figure 7a,c), but showed lower contrast when the background color was light (Figure 7b). Similarly, fingerprints labeled with magnetic powder showed high contrast when the background color was light (Figure 7d,e), but showed lower contrast when the background color was dark (Figure 7f). As mentioned above, the color contrast between the background and conventional powders should be high enough to ensure high developing contrast in fingerprint development. Therefore, the use of conventional, nonfluorescent powders was seriously restricted by the background color of the substrate. When green fluorescent powders were used, the developing contrast was enhanced by the green fluorescence. Thus, clear and well-defined fingerprint images could be captured under $254 \mathrm{~nm}$ UV radiation (Figure $7 \mathrm{~g}-\mathrm{i}$ ).

In contrast, fingerprints labeled with $\mathrm{NaYF}_{4}: \mathrm{Yb}, \mathrm{Er}$ UCNPs could be captured under $980 \mathrm{~nm}$ NIR radiation (Figure 7j-1) instead of the unsafe UV irradiation. Consequently, the fingerprint ridge details on all of the selected object surfaces were well-defined and had high contrast, sufficient quality, and strong UC fluorescence. Compared with fingerprint development using green fluorescent powders, the developing contrast of fingerprints labeled with $\mathrm{NaYF}_{4}$ : $\mathrm{Yb}, \mathrm{Er}$ UCNPs was markedly increased because of the strong UC fluorescence intensity. It should be noted that detailed features of the fingerprints such as sweat pores labeled by $\mathrm{NaYF}_{4}$ : $\mathrm{Yb}$,Er UCNPs could also be observed clearly (Figure S6 in the Supporting Information), due to their small size and suitable affinity, which was almost impossible to achieve by traditional powders. Therefore, $\mathrm{NaYF}_{4}$ : $\mathrm{Yb}, \mathrm{Er}$ UCNPs can indeed effectively provide high developing contrast and sensitivity for developing latent fingerprints. 


\subsubsection{Development of Latent Fingerprints on Substrates with Background}

Interference-To determine the background interference in latent fingerprint development using $\mathrm{NaYF}_{4}$ : $\mathrm{Yb}$,Er UCNPs as fluorescence labels, marbles with complex patterns were used as a smooth substrate. Fingerprints labeled with both bronze powders and magnetic powders showed low developing contrast due to serious background interference (Figure 8af), resulting in low sensitivity. Therefore, conventional, nonfluorescent powders were unsuitable for the development of fingerprints on multicolor background substrates. When green fluorescent powders or $\mathrm{NaYF}_{4}: \mathrm{Yb}$,Er UCNPs were used, the developing contrast was remarkably enhanced by the green fluorescence. Thus, clear and well-defined fingerprint images with high contrast, sufficient quality, and strong fluorescence could be captured under $254 \mathrm{~nm}$ UV radiation or $980 \mathrm{~nm}$ NIR radiation, without any background interference (Figure $8 \mathrm{~g}-1$ ). However, the developing contrast of fingerprints labeled with $\mathrm{NaYF}_{4}: \mathrm{Yb}, \mathrm{Er}$ UCNPs was higher than that of fingerprints labeled with green fluorescent powders. Therefore, our $\mathrm{NaYF}_{4}: \mathrm{Yb}$,Er UCNPs could be used for developing latent fingerprints without background interference.

\subsubsection{Development of Latent Fingerprints on Substrates with} Autofluorescence Interference-To determine the autofluorescence interference in latent fingerprint development using $\mathrm{NaYF}_{4}: \mathrm{Yb}, \mathrm{Er}$ UCNPs as fluorescence labels, smooth, fluorescent objects (note papers, Chinese paper money, and plastic plates) were used as a substrate. Fingerprints labeled with both bronze powder and magnetic powder showed low developing contrast because of severe background color interference (Figure 9a,c,f) and background pattern interference (Figure 9b,e), leading to low sensitivity. Although green fluorescent powders were used, the developing contrast was still very low because of strong autofluorescence interference from the substrate under $254 \mathrm{~nm} \mathrm{UV}$ radiation (Figure $9 \mathrm{~g}-\mathrm{i}$ ). As discussed above, conventional powders are unsuitable for developing the fingerprints on fluorescent substrates due to the strong autofluorescence interference. When the fingerprints were labeled with $\mathrm{NaYF}_{4}: \mathrm{Yb}, \mathrm{Er} \mathrm{UCNPs}$, details of the fingerprint ridge on all of the surfaces were well resolved with high contrast, sufficient quality, and strong UC fluorescence under $980 \mathrm{~nm}$ NIR radiation; background interference or autofluorescence interference were successfully avoided (Figure 9j-1). Therefore, our $\mathrm{NaYF}_{4}$ : $\mathrm{Yb}$,Er UCNPs could be used to develop latent fingerprints without autofluorescence interference.

\section{CONCLUSIONS}

We have optimized the solvothermal synthesis of $\mathrm{NaYF}_{4}: \mathrm{Yb}, \mathrm{Er}$ UCNPs to identify the optimal reaction temperature, reaction time, and oleic acid content, which led to improved fluorescence intensity under NIR irradiation. The $\mathrm{NaYF}_{4}: \mathrm{Yb}, \mathrm{Er}$ UCNPs synthesized at the optimized conditions were successfully used as a fluorescent label to develop latent fingerprints on the smooth substrates glass, ceramic tiles, marbles, polymeric materials, printed papers, and Chinese paper money. Compared with fingerprint development using traditional powders (bronze powder, magnetic powder, and green fluorescent powder), our development procedure using UCNPs is facile and exhibits high sensitivity, high contrast, low background interference, and low autofluorescence interference. 


\title{
Supplementary Material
}

Refer to Web version on PubMed Central for supplementary material.

\section{Acknowledgments}

\begin{abstract}
We gratefully acknowledge the financial support from the National Science Foundation of China (21205139), the Application and Innovation Project of Chinese Ministry of Public Security (2012YYCXXJXY127), and the Program for Liaoning Excellent Talents in University (LJQ2014130). Y.Z. and C.B.M. would like to acknowledge the financial support from the National Institutes of Health (EB015190), National Science Foundation (CMMI-1234957 and DMR-0847758), Department of Defense Peer Reviewed Medical Research Program (W81XWH-12-1-0384), Oklahoma Center for the Advancement of Science and Technology (HR14-160), and Oklahoma Center for Adult Stem Cell Research (434003).
\end{abstract}

\section{REFERENCES}

1. Choi MJ, Smoother T, Martin AA, McDonagh AM, Maynard PJ, Lennard C, Roux C. Fluorescent $\mathrm{TiO}_{2}$ Powders Prepared Using a New Perylene Diimide Dye: Applications in Latent Fingermark Detection. Forensic Sci. Int. 2007; 173:154-160. [PubMed: 17399926]

2. Oden S, Von Hofsten B. Detection of Fingerprints by the Ninhydrin Reaction. Nature. 1954; 173:449-450. [PubMed: 13144778]

3. Fung TC, Grimwood K, Shimmon R, Spindler X, Maynard P, Lennard C, Roux C. Investigation of Hydrogen Cyanide Generation from the Cyanoacrylate Fuming Process Used for Latent Fingermark Detection. Forensic Sci. Int. 2011; 212:143-149. [PubMed: 21737219]

4. Tahtouh M, Kalman JR, Reedy BJ. Synthesis and Characterization of Four Alkyl 2-Cyanoacrylate Monomers and Their Precursors for Use in Latent Fingerprint Detection. J. Polym. Sci. Polym. Chem. 2011; 49:257-277.

5. Kendall FG, Rehn BW. Rapid Method of Super Glue Fuming Application for the Development of Latent Fingerprints. J. Forensic Sci. 1983; 28:777-780.

6. Sodhi GS, Kaur J. Powder Method for Detecting Latent Fingrprints: A Review. Forensic Sci. Int. 2001; 120:172-176. [PubMed: 11473799]

7. Becue A, Champod C, Margot P. Use of Gold Nanoparticles as Molecular Intermediates for the Detection of Fingermarks. Forensic Sci. Int. 2007; 168:169-176. [PubMed: 16920302]

8. Sametband M, Shweky I, Banin U, Mandler D, Almog J. Application of Nanoparticles for the Enhancement of Latent Fingerprints. Chem. Commun. 2007:1142-1144.

9. Becue A, Scoundrianos A, Champod C, Margot P. Fingermark Detection Based on the in Situ Growth of Luminescent Nanoparticles-Towards a New Generation of Multimetal Deposition. Forensic Sci. Int. 2008; 179:39-43. [PubMed: 18502068]

10. Choi MJ, McDonagh AM, Maynard P, Roux C. Metal-Containing Nanoparticles and NanoStructured Particles in Fingermark Detection. Forensic Sci. Int. 2008; 179:87-97. [PubMed: 18565707]

11. Jin YJ, Luo YJ, Li GP, Li J, Wang YF, Yang RQ, Lu WT. Application of Photoluminescent CdS/ PAMAM Nanocomposites in Fingerprint Detection. Forensic Sci. Int. 2008; 179:34-38. [PubMed: 18513904]

12. Theaker BJ, Hudson KE, Rowell FJ. Doped Hydrophobic Silica Nano- and Micro- Particles as Novel Agents for Developing Latent Fingerprints. Forensic Sci. Int. 2008; 174:26-34. [PubMed: 17418514]

13. Becue A, Moret S, Champod C, Margot P. Use of Quantum Dots in Aqueous Solution to Detect Blood Fingermarks on Non-Porous Surfaces. Forensic Sci. Int. 2009; 191:36-41. [PubMed: 19576707]

14. Dilag J, Kobus H, Ellis AV. Cadmium Sulfide Quantum Dot/Chitosan Nanocomposites for Latent Fingermark Detection. Forensic Sci. Int. 2009; 187:97-102. [PubMed: 19356872]

15. Wang YF, Yang RQ, Wang YJ, Shi ZX, Liu JJ. Application of CdSe Nanoparticle Suspension for Developing Latent Fingermarks on the Sticky Side of Adhesives. Forensic Sci. Int. 2009; 185:9699. [PubMed: 19188035] 
16. Hussain I, Hussain SZ, Habib-ur-Rehman, Ihsan A, Rehman A, Khalid ZM, Brust M, Cooper AI. In Situ Growth of Gold Nanoparticles on Latent Fingerprints-from Forensic Applications to Inkjet Printed Nanoparticle Patterns. Nanoscale. 2010; 2:2575-2578. [PubMed: 20959933]

17. Jones BJ, Reynolds AJ, Richardson M, Sears VG. Nano-Scale Composition of Commercial White Powders for Development of Latent Fingerprints on Adhesives. Sci. Justice. 2010; 50:150-155. [PubMed: 20709276]

18. Liu JJ, Shi ZX, Yu YC, Yang RQ, Zuo SL. Water-Soluble Multicolored Fluorescent CdTe Quantum Dots: Synthesis and Application for Fingerprint Developing. J. Colloid Interface Sci. 2010; 342:278-282. [PubMed: 19939398]

19. Gao F, Lv CF, Han JX, Li XY, Wang Q, Zhang J, Chen C, Li Q, Sun XF, Zheng JC, Bao LR, Li X. CdTe Montmorillonite Nanocomposites: Control Synthesis, UV Radiation-Dependent Photoluminescence, and Enhanced Latent Fingerprint Detection. J. Phys. Chem. C. 2011; 115:21574-21583.

20. Gao F, Han JX, Zhang J, Li Q, Sun XF, Zheng JC, Bao LR, Li X, Liu ZL. The Synthesis of Newly Modified CdTe Quantum Dots and Their Application for Improvement of Latent Fingerprint Detection. Nanotechnology. 2011; 22:075705. [PubMed: 21233537]

21. Gao F, Han J, Lv C, Wang Q, Zhang J, Li Q, Bao L, Li X. Application of Core-Shell-Structured CdTe@ $\mathrm{SiO}_{2}$ Quantum Dots Synthesized via a Facile Solution Method for Improving Latent Fingerprint Detection. J. Nanopart. Res. 2012; 14:1-11. [PubMed: 22448125]

22. Wang J, Wei T, Li X, Zhang B, Wang J, Huang C, Yuan Q. Near-Infrared-Light-Mediated Imaging of Latent Fingerprints Based on Molecular Recognition. Angew. Chem., Int. Ed. 2014; 53:16161620.

23. Auzel F. Upconversion and Anti-Stokes Processes with f and d Ions in Solids. Chem. Rev. 2004; 104:139-173. [PubMed: 14719973]

24. Shen J, Sun LD, Yan CH. Luminescent Rare Earth Nanomaterials for Bioprobe Applications. Dalton Trans. 2008; 42:5687-5697. [PubMed: 18941653]

25. Vetrone F, Capobianco JA. Lanthanide-Doped Fluoride Nanoparticles: Luminescence, Upconversion, and Biological Applications. Int. J. Nanotechnol. 2008; 5:1306-1339.

26. Rahman P, Green M. The Synthesis of Rare Earth Fluoride Based Nanoparticles. Nanoscale. 2009; 1:214-224. [PubMed: 20644840]

27. Chatterjee DK, Gnanasammandhan MK, Zhang Y. Small Upconverting Fluorescent Nanoparticles for Biomedical Applications. Small. 2010; 6:2781-2795. [PubMed: 21064086]

28. Li CX, Lin J. Rare Earth Fluoride Nano-/Microcrystals: Synthesis, Surface Modification and Application. J. Mater. Chem. 2010; 20:6831-6847.

29. Mader HS, Kele P, Saleh SM, Wolfbeis OS. Upconverting Luminescent Nanoparticles for Use in Bioconjugation and Bioimaging. Curr. Opin. Chem. Biol. 2010; 14:582-596. [PubMed: 20829098]

30. Wang F, Banerjee D, Liu YS, Chen XY, Liu XG. Upconversion Nanoparticles in Biological Labeling, Imaging, and Therapy. Analyst. 2010; 135:1839-1854. [PubMed: 20485777]

31. Schafer H, Haase M. Upconverting Nanoparticles. Angew. Chem., Int. Ed. 2011; 50:5808-5829.

32. Wang M, Abbineni G, Clevenger A, Mao CB, Xu SK. Upconversion Nanoparticles: Synthesis, Surface Modification and Biological Applications. Nanomed.: Nanotechnol., Biol. Med. 2011; 7:710-729.

33. Wang M, Mi CC, Wang WX, Liu CH, Wu YF, Xu ZR, Mao CB, Xu SK. Immunolabeling and NIRExcited Fluorescent Imaging of HeLa Cells by Using $\mathrm{NaYF}_{4}$ : Yb,Er Upconversion Nanoparticles. ACS Nano. 2009; 3:1580-1586. [PubMed: 19476317]

34. Wang M, Mi CC, Zhang YX, Liu JL, Li F, Mao CB, Xu SK. NIR-Responsive Silica-Coated $\mathrm{NaYbF}_{4}: \mathrm{Er} / \mathrm{Tm} / \mathrm{Ho}$ Upconversion Fluorescent Nanoparticles with Tunable Emission Colors and Their Applications in Immunolabeling and Fluorescent Imaging of Cancer Cells. J. Phys. Chem. C. 2009; 113:19021-19027.

35. Chen J, Guo CR, Wang M, Huang L, Wang LP, Mi CC, Li J, Fang XX, Mao CB, Xu SK. Controllable Synthesis of $\mathrm{NaYF}_{4}: \mathrm{Yb}$,Er Upconversion Nanophosphors and Their Applications to in vivo Imaging of Caenorhabdits Elegans. J. Mater. Chem. 2011; 21:2632-2638. [PubMed: 21666862] 
36. Mi CC, Zhang JP, Gao HY, Wu XL, Wang M, Wu YF, Di YQ, Xu ZR, Mao CB, Xu SK. Multifunctional Nanocomposites of Superparamagnetic $\left(\mathrm{Fe}_{3} \mathrm{O}_{4}\right)$ and NIR-Responsive Rare EarthDoped Up-Conversion Fluorescent $\left(\mathrm{NaYF}_{4}: \mathrm{Yb}, \mathrm{Er}\right)$ Nanoparticles and Their Applications in Biolabeling and Fluorescent Imaging of Cancer Cells. Nanoscale. 2010; 2:1141-1148. [PubMed: 20648340]

37. Mi CC, Tian ZH, Cao C, Wang ZJ, Mao CB, Xu SK. Novel Microwave-Assisted Solvothermal Synthesis of $\mathrm{NaYF}_{4}: \mathrm{Yb}, \mathrm{Er}$ Upconversion Nanoparticles and Their Application in Cancer Cell Imaging. Langmuir. 2011; 27:14632-14637. [PubMed: 22029665]

38. Wang M, Hou W, Mi CC, Wang WX, Xu ZR, Teng HH, Mao CB, Xu SK. Immunoassay of Goat Antihuman Immunoglobulin G Antibody Based on Luminescence Resonance Energy Transfer Between Near-Infrared Responsive $\mathrm{NaYF}_{4}$ : $\mathrm{Yb}$,Er Upconversion Fluorescent Nanoparticles and Gold Nanoparticles. Anal. Chem. 2009; 81:8783-8789. [PubMed: 19807113]

39. Ma RL, Bullock E, Maynard P, Reedy B, Shimmon R, Lennard C, Roux C, McDonagh A. Fingermark Detection on Non-Porous and Semi-Porous Surfaces Using $\mathrm{NaYF}_{4}$ :Er, Yb UpConverter Particles. Forensic Sci. Int. 2011; 207:145-149. [PubMed: 20980110]

40. Ma RL, Shimmon R, McDonagh A, Maynard P, Lennard C, Roux C. Fingermark Detection on Non-Porous and Semi-Porous Surfaces Using $\mathrm{YVO}_{4}$ :Er,Yb Luminescent Upconverting Particles. Forensic Sci. Int. 2012; 217:e23-e26. [PubMed: 22047749]

41. Thoma RE, Insley H, Hebert GM. The Sodium Fluoride-Lanthanide Trifluoride Systems. Inorg. Chem. 1966; 5:1222-1229.

42. Mai HX, Zhang YW, Si R, Yan ZG, Sun LD, You LP, Yan CH. High-Quality Sodium Rare-Earth Fluoride Nanocrystals: Controlled Synthesis and Optical Properties. J. Am. Chem. Soc. 2006; 128:6426-6436. [PubMed: 16683808] 

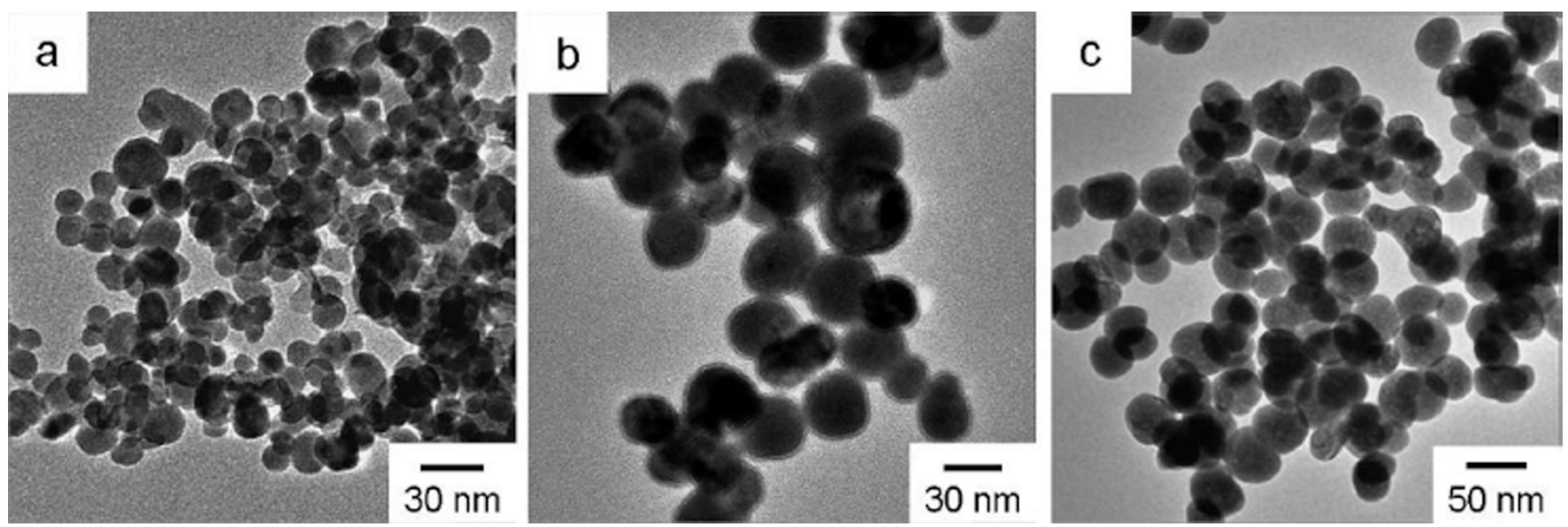

Figure 1.

TEM images of $\mathrm{NaYF}_{4}: \mathrm{Yb}, \mathrm{Er}$ UCNPs synthesized at $150{ }^{\circ} \mathrm{C}$ after various reaction times: (a) $2 \mathrm{~h}$, (b) $8 \mathrm{~h}$, and (c) $24 \mathrm{~h}$. 


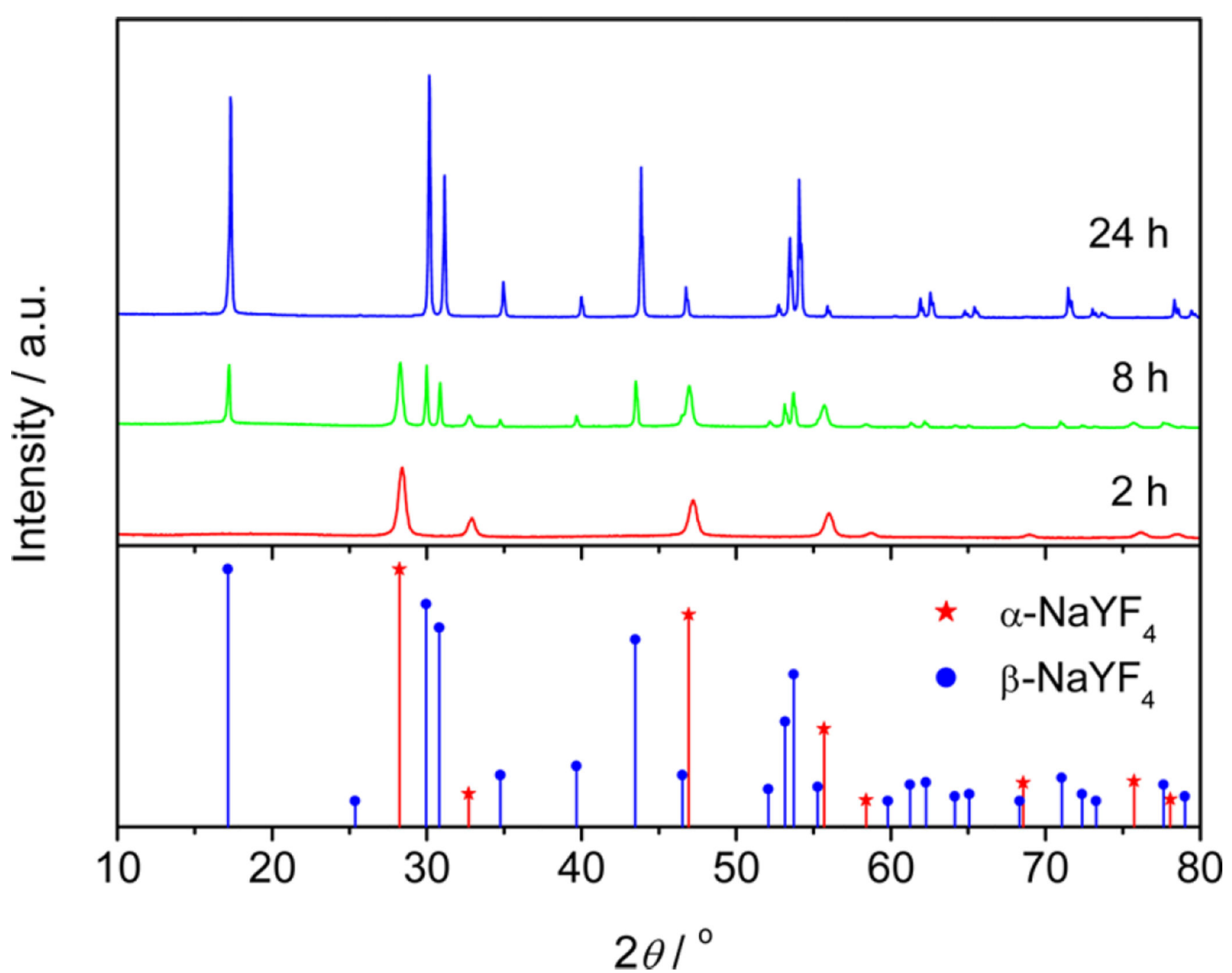

Figure 2.

XRD patterns of $\mathrm{NaYF}_{4}: \mathrm{Yb}$,Er UCNPs synthesized after different reaction times at a reaction temperature of $150{ }^{\circ} \mathrm{C}$. 


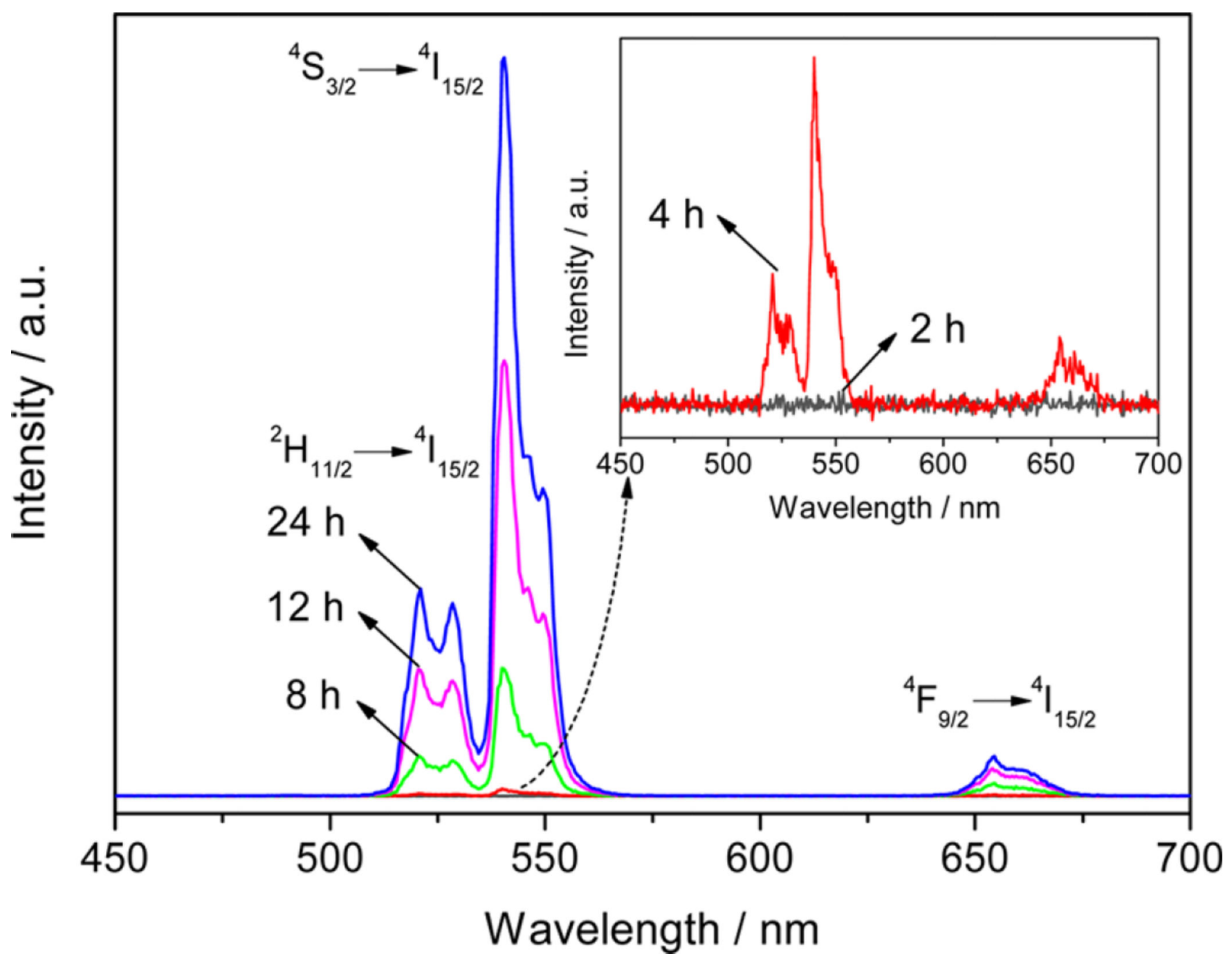

Figure 3.

UC fluorescence spectra of $\mathrm{NaYF}_{4}: \mathrm{Yb}$,Er UCNPs synthesized at different reaction times at a reaction temperature of $150{ }^{\circ} \mathrm{C}$. The excitation wavelength was $980 \mathrm{~nm}$. 

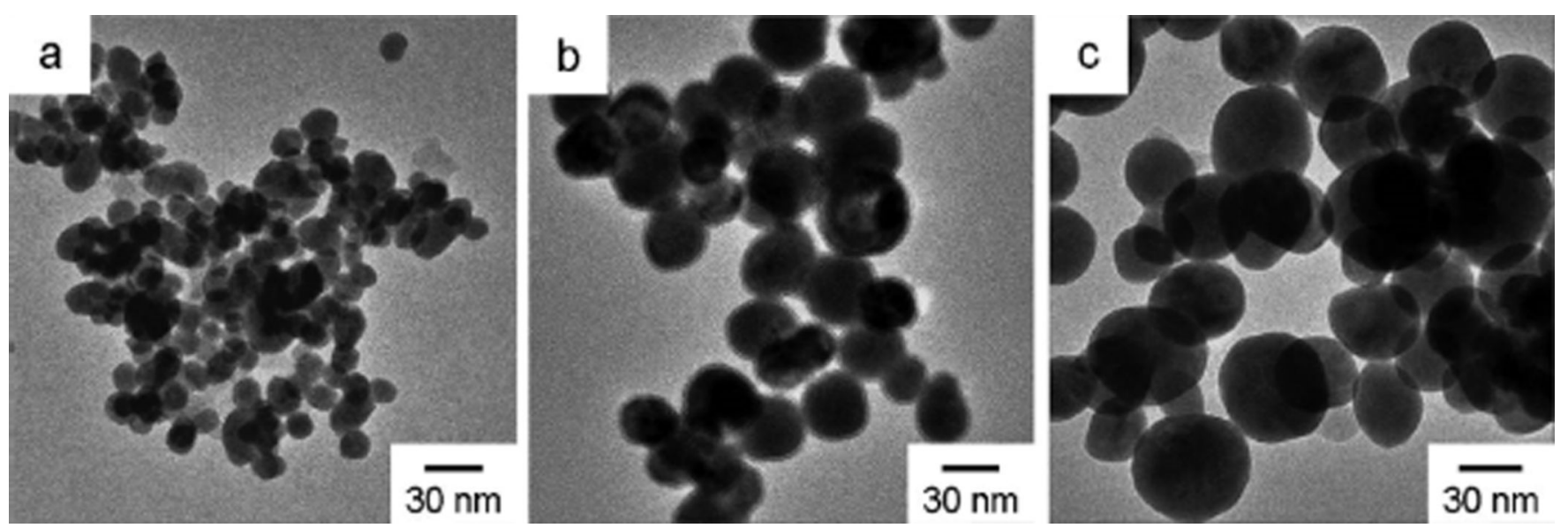

Figure 4.

TEM images of $\mathrm{NaYF}_{4}: \mathrm{Yb}$,Er UCNPs synthesized at various reaction temperatures for $8 \mathrm{~h}$ : (a) 100 , (b) 150 , and (c) $200^{\circ} \mathrm{C}$. 


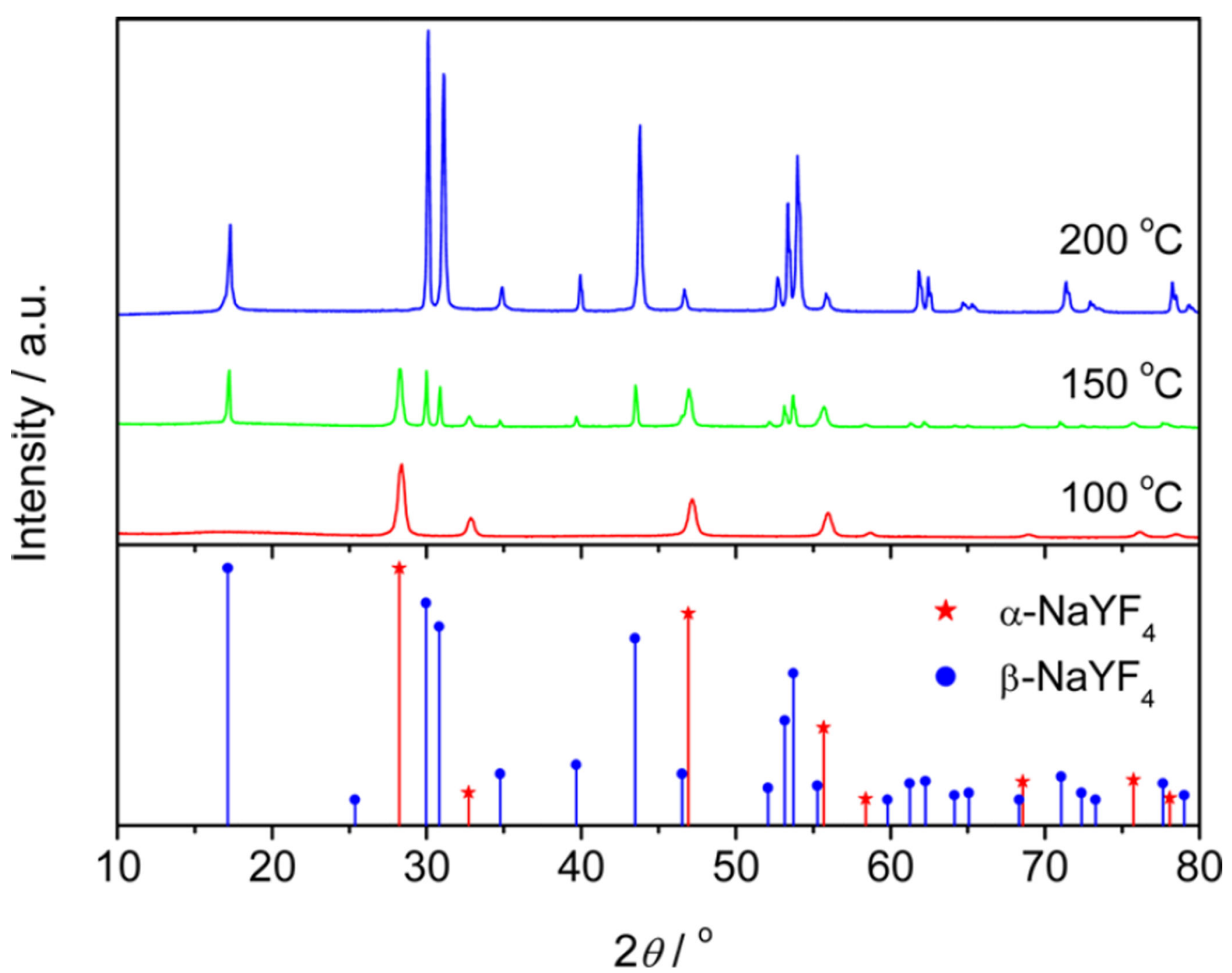

Figure 5.

XRD patterns of $\mathrm{NaYF}_{4}: \mathrm{Yb}, \mathrm{Er}$ UCNPs synthesized at various reaction temperatures for $8 \mathrm{~h}$. 


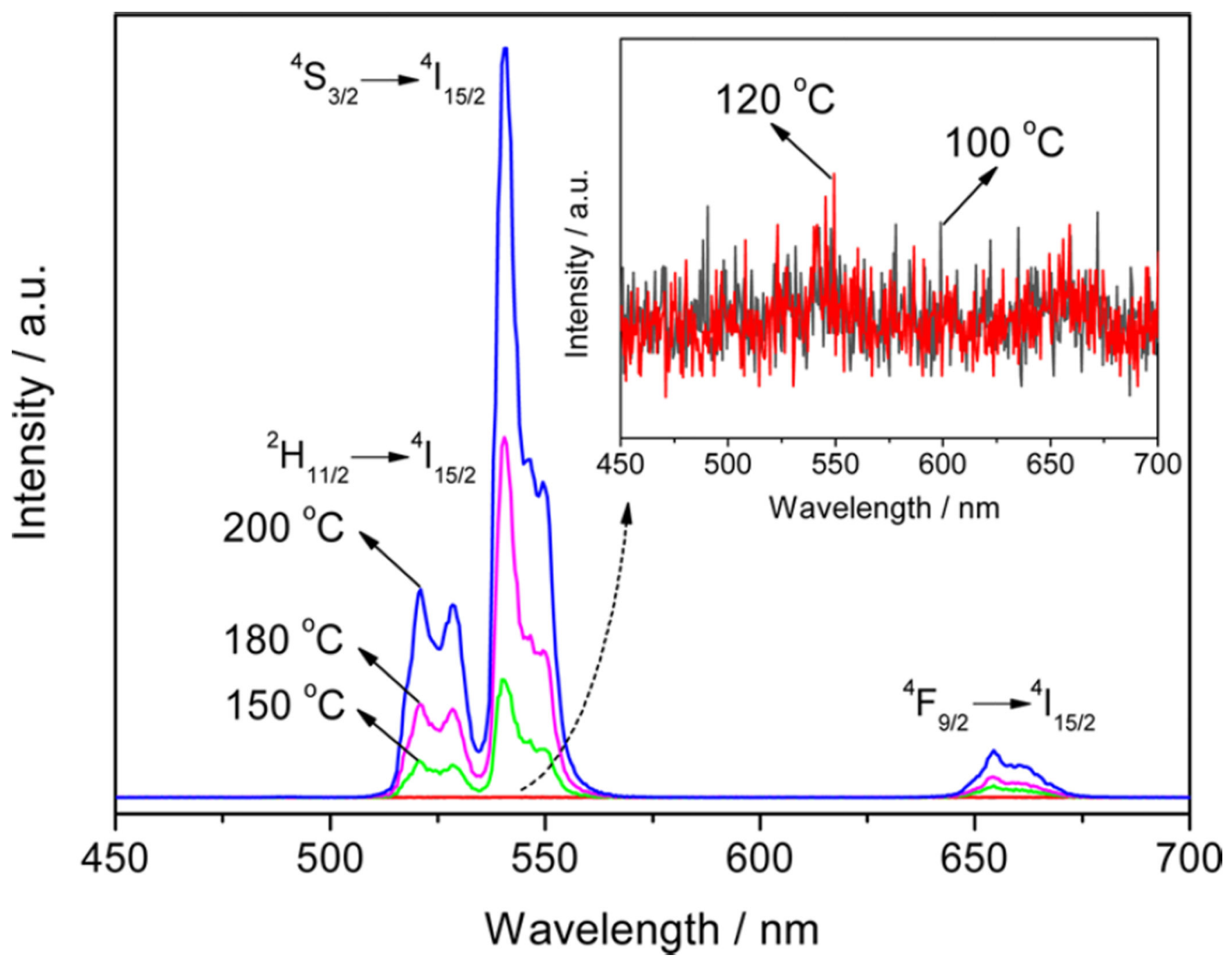

Figure 6.

UC fluorescence spectra of $\mathrm{NaYF}_{4}: \mathrm{Yb}$,Er UCNPs synthesized at different reaction temperatures for $8 \mathrm{~h}$. The excitation wavelength was $980 \mathrm{~nm}$. 

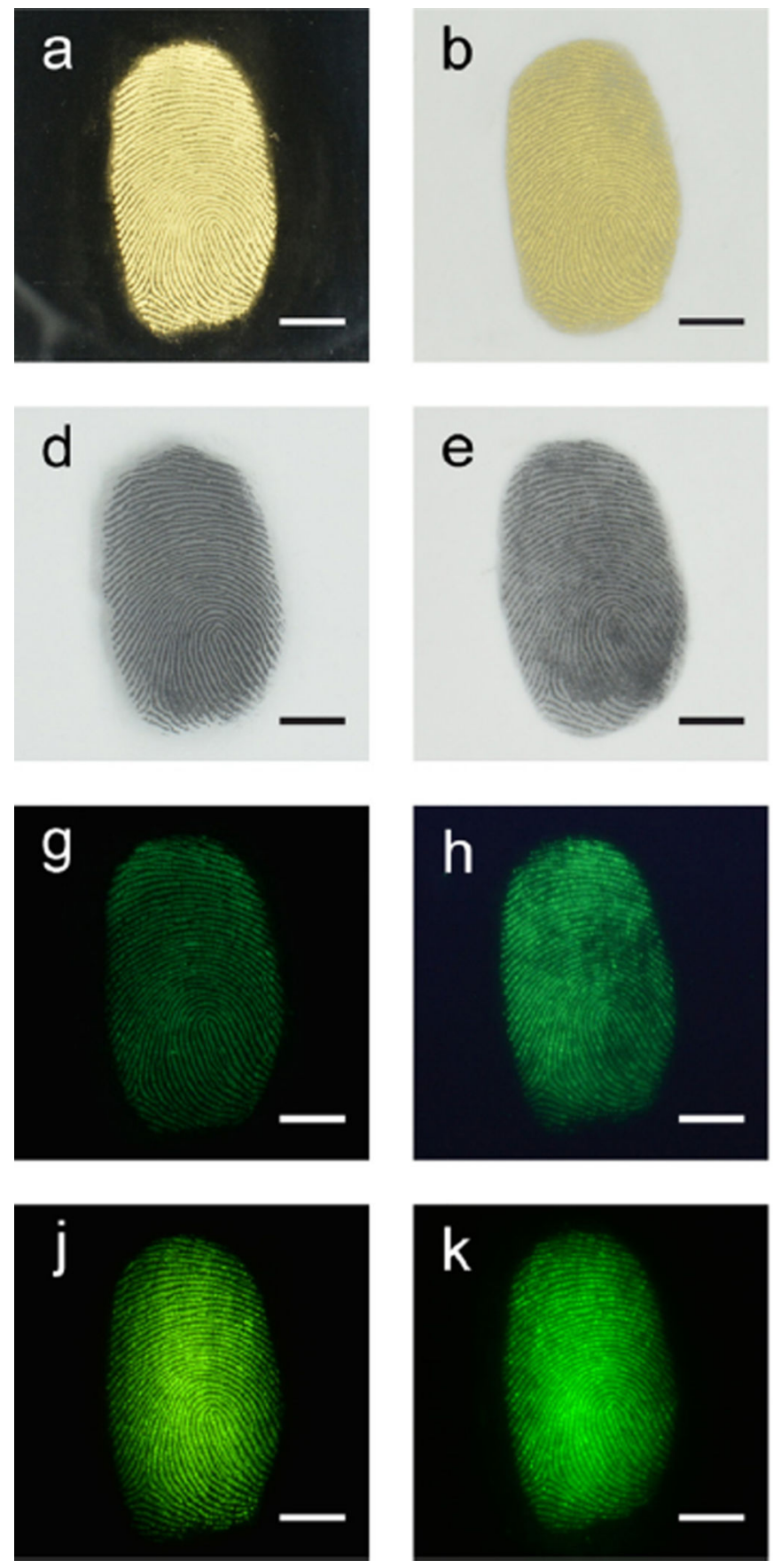
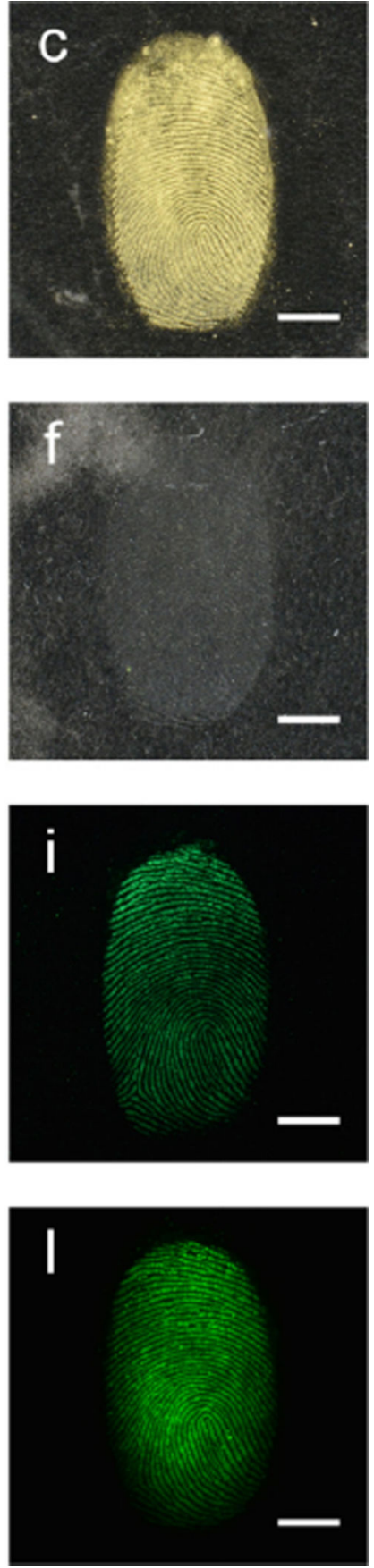

Figure 7.

Development of latent fingerprints on various substrates, using different types of powders: $(\mathrm{a}-\mathrm{c})$ bronze powders, in bright field; $(\mathrm{d}-\mathrm{f})$ magnetic powders, in bright field; $(\mathrm{g}-\mathrm{i})$ green fluorescent powders, in dark field and under $254 \mathrm{~nm} \mathrm{UV}$ excitation; and (j-1) $\mathrm{NaYF}_{4}: \mathrm{Yb}, \mathrm{Er}$ UCNPs, in dark field and under $980 \mathrm{~nm}$ NIR excitation. Left, middle, and right rows contain fingerprints printed on transparent glass, white ceramic tiles, and black marbles, respectively. The scale bar corresponds to $5.0 \mathrm{~mm}$. 

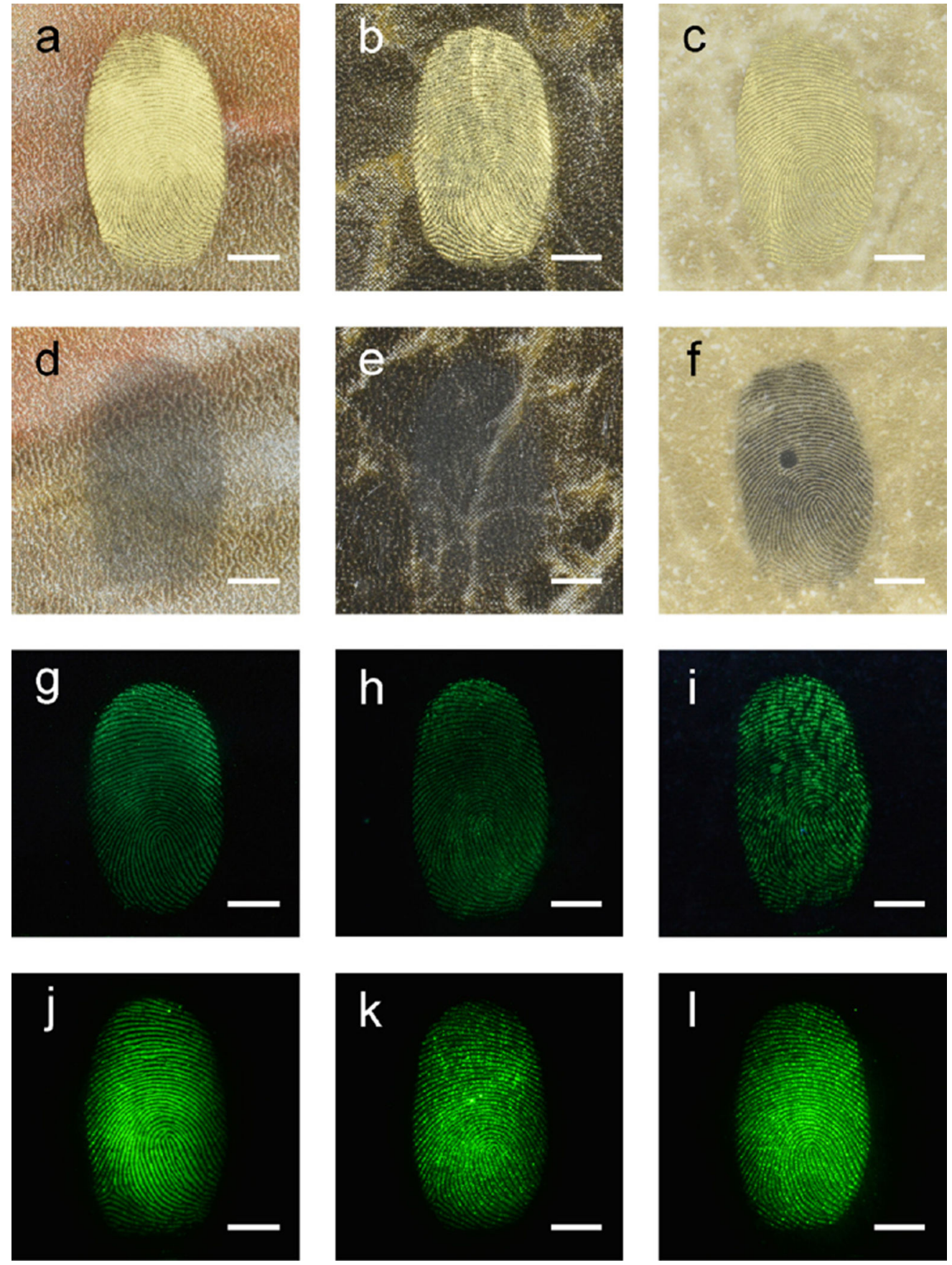

Figure 8.

Latent fingerprint development on various marbles with different surface textures using different types of powders: $(\mathrm{a}-\mathrm{c})$ bronze powders, in bright field; $(\mathrm{d}-\mathrm{f})$ magnetic powders, in bright field; ( $\mathrm{g}-\mathrm{i}$ ) green fluorescent powders, in dark field and under $254 \mathrm{~nm}$ UV excitation; and $(\mathrm{j}-1) \mathrm{NaYF}_{4}: \mathrm{Yb}, \mathrm{Er}$ UCNPs, in dark field and under $980 \mathrm{~nm}$ NIR excitation. The scale bar corresponds to $5.0 \mathrm{~mm}$. 


\section{a}
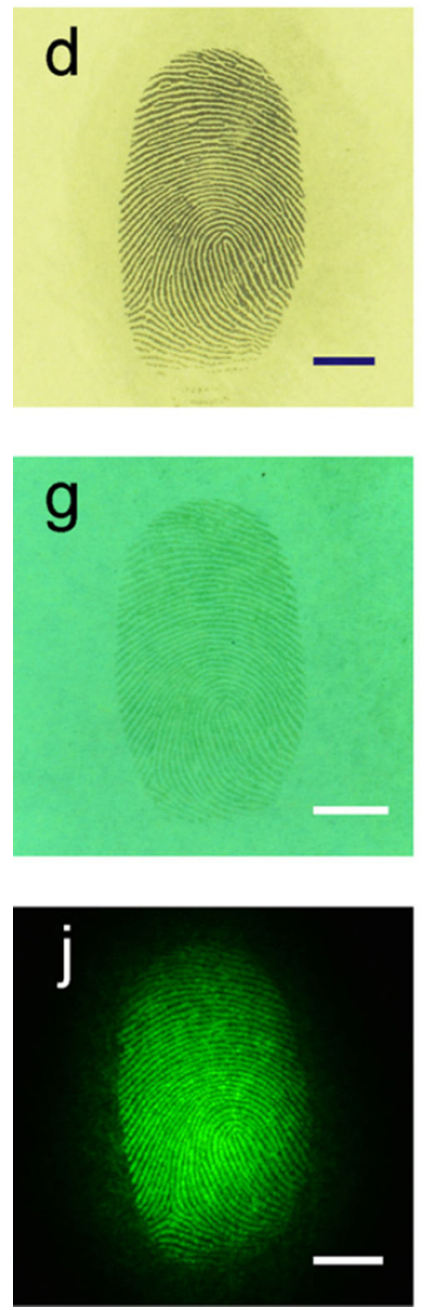
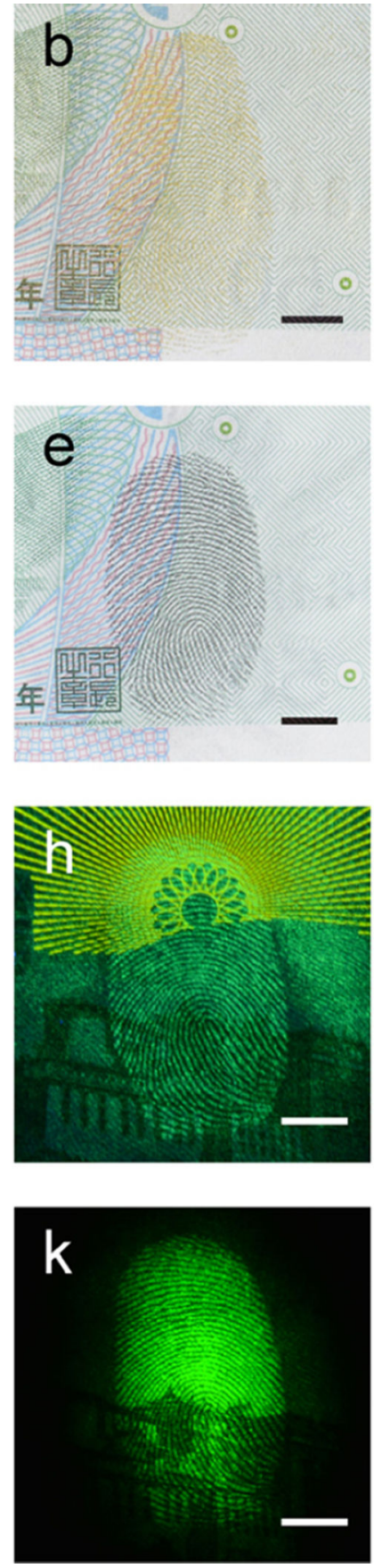
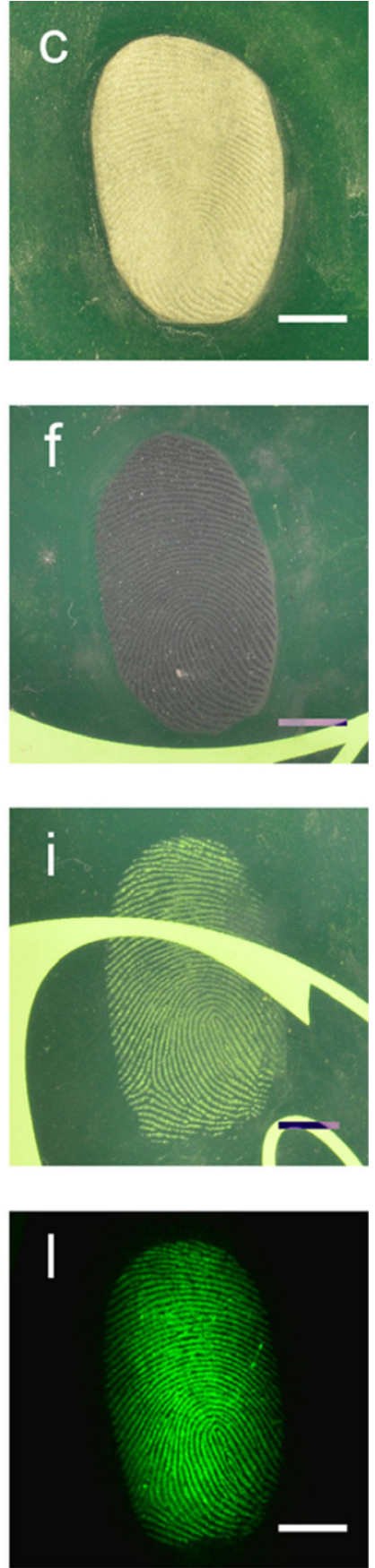

Figure 9.

Latent fingerprint development on various fluorescent substrates using different types of powders: (a-c) bronze powders, in bright field; (d-f) magnetic powders, in bright field; ( $\mathrm{g}-\mathrm{i}$ ) green fluorescent powders, in dark field and under $254 \mathrm{~nm}$ UV excitation; and (j-1) $\mathrm{NaYF}_{4}: \mathrm{Yb}$,Er UCNPs, in dark field and under $980 \mathrm{~nm}$ NIR excitation. Left, middle, and right rows comprise fingerprints on note papers, Chinese paper money, and plastic plates, respectively. The scale bar corresponds to $5.0 \mathrm{~mm}$. 


\section{Solvothermal Synthesis $\Rightarrow$ Synthetic Optimization}
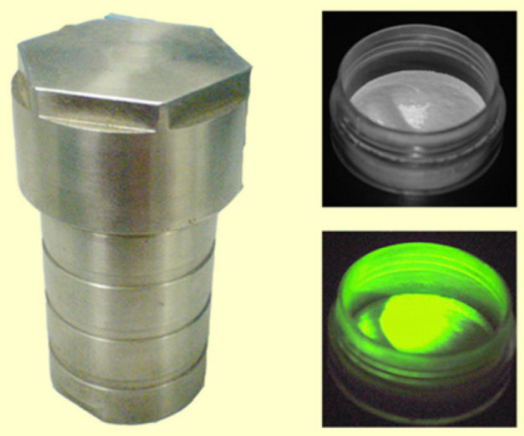

Reaction Parameters:

- Reaction Time

- Reaction Temperature

- Volume of Oleic Acid

Aims:

- Small Particle Size

- Pure Hexagonal Phase

- High Fluorescence Intensity
Fingerprint Development

substrates with a
single background
color
substrates with
multiple background
colors
substrates with
strong background
autofluorescence

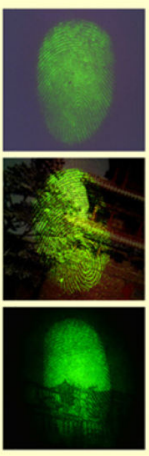

Scheme 1.

General Idea of This Study 